\title{
Genotype-environment interaction and stability analysis of four fine rice varieties
}

\author{
P. L. Biswas ${ }^{1}$, U. K. Nath ${ }^{2}$, S. Ghosal ${ }^{1}$ and A. K. Patwary ${ }^{2}$ \\ ${ }^{1}$ Plant Breeding Division, BRRI, Gazipur and ${ }^{2}$ Department of Genetics and Plant Breeding, Bangladesh Agricultural \\ University, Mymensingh-2202, Bangladesh. Email: ujjalnath@gmail.com
}

\begin{abstract}
Genotype-environment interactions through different stability parameters and performance traits of four fine rice genotypes were studied. The traits were; days to $50 \%$ flowering, days to maturity, plant height (cm), number of effective tillers per hill, panicle length $(\mathrm{cm})$, number of fertile grains per panicle, number of sterile grains per panicle and yield ( $t / h a)$ in four fine rice genotypes across nine environments along with experimental farm of Genetics and Plant Breeding department, Bangladesh Agricultural University (BAU) Mymensingh. Significant differences were observed for genotypes, environments and genotypes-environment interaction. Stability analysis after Eberhat and Russell's model suggested that the genotypes used in study were more or less responsive to environmental changes. Most of the genotypes performed better in Comilla. BAU125 was found stable for effective tillers per hill and comparatively less sensitive to other genotypes in panicle length and number of sterile grains per panicle. BR5 was stable for days to maturity and plant height whereas Kalizira performed better than other genotypes for fertile grains per panicle. In general, only the genotype BAU125 was found stable for effective tillers per hill, panicle length and lowest number of sterile grains per panicle.
\end{abstract}

Keywords: Fine rice, Genotype-environment interaction, Stability

\section{Introduction}

Rice feeds more than half of world population. The demand of fine rice is always high although it possesses lower yield potentiality than HYV (High Yielding Variety). Yield is a complex character which is dependent on a number of other characters and is highly influenced by many genetic factors as well as environmental fluctuation. Genotypes which can adjust its phenotypic state in response to environmental fluctuations in such a way that it gives maximum stable economic return can be termed as well "buffered" or stable (Allard and Bardshaw,1964).In plant breeding programme, potential genotypes are usually evaluated in different environments before selecting desirable ones. For stabilizing yield it is necessary to identify the stable genotypes suitable for wide range of environments. To identify such genotypes, G-E interactions are of major concern for a breeder, because such interactions confound the selection of the superior cultivars by altering their relative productiveness in different environments (Eagles and Frey, 1977). Varietals study in yield with respect to wide range of environments is one of the most desired properties of genotypes to fit the crop under available cropping pattern. So, wider adaptability and stability are prime consideration in formulating efficient breeding programme. Stability analysis is a good technique for measuring the adaptability of different crop varieties to varying environments (Morales et al., 1991). Therefore, present study was undertaken to estimate the G-E interactions through stability parameters and performance of some traits of four fine rice genotypes across environments and to identify the suitable genotypes for future breeding programme.

\section{Materials and Methods}

The experiment was conducted at nine different environments i.e. nine districts viz. Dhaka (Env.-01), Comilla (Env.-02), Sylhet (Env.-03), Barisal (Env.-04), Bogra (Env.-05), Dinajpur (Env.-06), Rajshahi (Env.-07), Jessore (Env.-08) along with experimental farm, Department of Genetics and Plant Breeding, Bangladesh Agricultural University (BAU), Mymensingh (Env.-09), Bangladesh. Four fine rice genotypes viz.BAU125, BR5, Kalizira and Kataribhog were used in the study. The experiment was laid out in a randomized complete block design with three replications in each environment. The unit plot size in a replication was $6 \mathrm{~m}$ in length and $5 \mathrm{~m}$ in width, 25 rows of 1000 hills per genotypes keeping row to row distance $20 \mathrm{~cm}$ and hill to hill distance $15 \mathrm{~cm}$. In all the experimental locations, same operational procedures were followed. Seeds were sown on $7^{\text {th }}$ July, 2000 and 32 days old seedlings were 
transplanted on $9^{\text {th }}$ August, 2000. Fertilizer was applied @100: 90: $70 \mathrm{~kg} \mathrm{ha}^{-1}$ of urea, TSP and MOP. One-third of urea, whole amount of TSP and MOP were applied as basal dose during final land preparation. Remaining two-third of the urea was applied in two splits, first at 21 days after transplanting and the other before panicle initiation. Normal cultural practices were followed as and whenever necessary. Data on eight characters were considered and presented in this paper. The genotypesenvironment interactions and stability analysis were done following the method suggested by Eberhart and Russell (1966) also quoted by Singh and Chaudhury (1985) and Dabholkar (1992).

\section{Results and Discussion}

The results of the combined analysis of variance after Eberhart and Rusell's model are presented in Table 1. The mean squares for genotypes and environments for all the traits under study were highly significant $(p \leq 0.01)$; suggesting the existence of considerable variation among genotypes as well as environments. The genotype-environment interaction when tested against pooled error was found significant for all the characters, indicating that all the traits were highly influenced by the change in environments leading to extension of analysis for estimating stability parameters. The linear portion of G$E$ interaction was highly significant $(p \leq 0.01)$ for all the characters except three such as plant height, number of effective tillers per hill and number of fertile grains per panicle. Thus the prediction of the genotypes in the environments appeared to be feasible for five characters under study.

Table 1. Combined analysis of variance (MS) for eight characters in a genotype-environment interaction study in fine rice after Eberhart and Russell model

\begin{tabular}{|c|c|c|c|c|c|c|c|c|c|}
\hline Source of variation & d.f. & $\begin{array}{c}\text { Days to } \\
50 \% \\
\text { flowering }\end{array}$ & $\begin{array}{l}\text { Days to } \\
\text { maturity }\end{array}$ & $\begin{array}{l}\text { Plant } \\
\text { height } \\
(\mathrm{cm})\end{array}$ & $\begin{array}{c}\text { No. } \\
\text { effective } \\
\text { tillers/hill }\end{array}$ & $\begin{array}{l}\text { Panicle } \\
\text { length } \\
\text { (cm) }\end{array}$ & $\begin{array}{c}\text { No. of fertile } \\
\text { grains / } \\
\text { panicle }\end{array}$ & $\begin{array}{c}\text { No. sterile } \\
\text { grains / } \\
\text { panicle }\end{array}$ & $\begin{array}{l}\text { Yield } \\
\text { (t/ha) }\end{array}$ \\
\hline Genotypes & 3 & $24.705^{\star \star}$ & $52.889^{* \star}$ & $300.005^{*}$ & $4.434^{* *}$ & $8.298^{* *}$ & $2873.045^{* *}$ & $367.959 * *$ & $0.434^{* *}$ \\
\hline Environments & 8 & $10.881^{\star *}$ & $87.815^{\star *}$ & $528.609^{\star *}$ & $23.328^{* *}$ & $68.008^{* *}$ & $3586.151^{* *}$ & $531.017^{* *}$ & $2.927^{* *}$ \\
\hline Gen x Env. & 24 & $3.026^{\star *}$ & $4.417^{\star \star}$ & $265.325^{*}$ & $2.545^{\star *}$ & $7.679^{\star *}$ & $895.631^{\star \star}$ & $196.806^{\star *}$ & $0.257^{* *}$ \\
\hline Env. +Gen.x Env. & 32 & $1.663^{\star *}$ & $8.422^{\star \star}$ & $110.379^{* *}$ & $2.580^{\star \star}$ & $7.587^{\star \star}$ & $522.757^{\star \star}$ & $93.452^{\star \star}$ & $0.308^{\star \star}$ \\
\hline Env.(Linear) & 1 & $29.012^{* \star}$ & $234.168^{\star *}$ & $1409.800^{\star *}$ & $62.192^{* *}$ & $181.368^{* *}$ & $9563.168^{\star *}$ & $1415.972^{* *}$ & $7.804^{\star \star}$ \\
\hline Gen. x Env.(Linear) & 3 & $1.979^{* *}$ & $5.052^{* *}$ & 46.965 & 0.983 & $9.567^{* *}$ & 178.219 & $300.188^{* *}$ & $0.230^{* \star}$ \\
\hline Pooled deviation & 28 & $0.653^{\star *}$ & $0.721^{* *}$ & $70.766^{\star *}$ & 0.622 & $1.168^{* *}$ & $236.8^{\star *}$ & $24.068^{\star *}$ & $0.049^{\star \star *}$ \\
\hline Pooled error & 72 & 0.245 & 0.163 & 2.622 & 0.492 & 0.195 & 40.826 & 5.032 & 0.002 \\
\hline
\end{tabular}

${ }^{*} p \leq 0.05$ and ** $p \leq 0.01$

The mean performance of the individual genotype along with their stability parameters $\left(p_{i,}, b_{i}\right.$ and $\left.s^{2} d_{i}\right)$ for days to $50 \%$ flowering is presented in Table 2 . From the environmental mean it was observed that Env.02 was the most favorable environment. Analysis of the stability parameters of the individual genotypes indicated that all the genotypes showed individual linear response. However, two of the genotypes BR5 and Kataribhog showed combined $b_{i}$ and $s^{2} d_{i}$ sensitivity which suggested that both linear and non linear components were responsible for significant genotype-environment interaction. Genotype BAU125, Kalizira and Kataribhog had the negative phenotypic indices, therefore, they were desirable genotypes for this character. Genotypes BAU125 and Kalizira showed $b_{i}$ value higher than unity with non-significant $s^{2} d_{i}$ values, indicating its suitability only for favorable environment condition. Estimation of all of three stability parameters, it appeared that there was no stable genotype against this character.

\section{Days to maturity}

The stability parameters along with the average days to maturity of different genotypes and environment are presented in the Table 2. From the environmental mean it was observed that Env.-5 was the favorable and Env.-3 was the unfavorable one. Analysis of stability parameters of individual genotypes indicated that three genotypes (BAU125, Kalizira and Kataribhog) out of four showed combine $b_{i}$ and $s^{2} d_{i}$ sensitivity suggesting either linear or non-linear component alone or their cumulative effects were responsible for significant genotype-environment interaction. Genotype BR5 showed $b_{i}$ value higher than unity with non-significant $\mathrm{s}^{2} \mathrm{~d}_{\mathrm{i}}$ indicating their suitability for in better environmental condition. All the genotypes except BR5 had the negative phenotypic indices, therefore, they were desirable genotypes for this character. Estimating all the stability parameters it appeared that genotype BR5 was relatively stable in changing environment. 
Table 2. Different important agronomical traits including average days to $50 \%$ flowering, days to maturity, panicle length, number of sterile grains per panicle and yield: phenotypic index ( $\mathrm{Pi})$, regression (bi) and deviation from regression ( $S^{2}$ di) for four rice genotypes evaluated under nine different environments using Eberhart and Russell model

\begin{tabular}{|c|c|c|c|c|c|c|c|c|c|c|c|c|c|c|c|c|c|c|}
\hline \multirow[b]{3}{*}{ Env. } & \multicolumn{18}{|c|}{ Characters } \\
\hline & \multicolumn{6}{|c|}{ Days to $50 \%$ flowering } & \multicolumn{6}{|c|}{ Days to maturity } & \multicolumn{6}{|c|}{ Panicle length } \\
\hline & BAU125 & BR5 & Kalizira & Katari & Mean & $\begin{array}{l}\text { Env. } \\
\text { Index }\end{array}$ & BAU125 & BR5 & Kalizira & Katari & Mean & $\begin{array}{l}\text { Env. } \\
\text { Index }\end{array}$ & BAU125 & BR5 & Kalizira & Katari & Mean & $\begin{array}{l}\text { Env. } \\
\text { Index }\end{array}$ \\
\hline Env.1 & 102.8 & 108.5 & 104.5 & 101.3 & 104.3 & 1.85 & 142 & 148 & 144 & 141 & 143.8 & 2.46 & 22.9 & 22.2 & 23.9 & 24.3 & 23.3 & 0.36 \\
\hline Env.2 & 100.7 & 104.2 & 101.5 & 100 & 101.6 & -0.86 & 139 & 142 & 137 & 134 & 138 & -3.37 & 23.2 & 21.4 & 24.7 & 24.3 & 23.4 & 0.4 \\
\hline Env.3 & 101.2 & 106 & 103.5 & 103.7 & 103.6 & 1.14 & 144 & 149 & 146 & 144 & 145.8 & 4.38 & 26.2 & 21.5 & 22.7 & 24.7 & 23.8 & 0.78 \\
\hline Env.4 & 101.2 & 103.3 & 102.2 & 103.2 & 102.5 & 0.02 & 141 & 143 & 139 & 139 & 140.5 & -0.87 & 22.4 & 16.9 & 13.1 & 16.7 & 17.3 & -5.7 \\
\hline Env.5 & 99.2 & 104.8 & 101.2 & 101.7 & 101.8 & -0.73 & 137 & 141 & 136 & 137 & 137.7 & -3.62 & 24.7 & 22.5 & 24.3 & 22.3 & 23.5 & 0.48 \\
\hline Env.6 & 100.2 & 104 & 108.8 & 102 & 102 & -0.44 & 141 & 146 & 143 & 139 & 142.3 & 0.88 & 25.1 & 22.4 & 22.3 & 22.3 & 23.1 & 0.06 \\
\hline Env.7 & 99.3 & 103.5 & 101.2 & 102 & 101.5 & -0.94 & 139 & 144 & 137 & 139 & 139.6 & -1.62 & 26.4 & 25.7 & 25.6 & 27.7 & 26.4 & 3.38 \\
\hline Env.8 & 100.5 & 102.8 & 102.5 & 102.7 & 102.1 & $\begin{array}{l}-0.32 \\
\end{array}$ & 141 & 144 & 139 & 140 & 141 & -0.37 & 23.2 & 22.2 & 23.7 & 21.7 & 22.7 & -0.29 \\
\hline Env.9 & 101.5 & 105.2 & 101.8 & 102.3 & 102.7 & 0.27 & 142 & 147 & 144 & 141 & 143.5 & 2.13 & 23.3 & 21.9 & 24.1 & 24.7 & 23.5 & 0.51 \\
\hline Mean & 100.72 & 104.7 & 102.24 & 102.09 & 102.4 & & 140.7 & 144.9 & 140.6 & 139 & 141.4 & & 24.16 & 21.86 & 22.7 & 23.18 & 22.98 & \\
\hline $\mathrm{Pi}$ & -1.72 & 2.26 & -0.19 & -0.35 & & & -0.7 & 3.52 & $\begin{array}{l}-0.78 \\
\end{array}$ & -2.04 & & & 1.18 & -1.12 & -0.26 & 0.2 & & \\
\hline bi & 1.039 ** & $1.532^{* \star}$ & $1.122^{\star *}$ & $0.363^{*}$ & & & $0.728^{\star *}$ & $1.004^{\star \star}$ & $1.353^{* \star}$ & $0.943^{* *}$ & & & $0.405^{*}$ & 0.910 ** & $1.478^{\star \star}$ & $1.207^{\star \star}$ & & \\
\hline $\mathrm{S}^{2} \mathrm{di}$ & 0.006 & $0.714^{*}$ & -0.157 & $0.901^{*}$ & & & $0.107^{\star}$ & -0.054 & $0.457^{* *}$ & $1.100^{* *}$ & & & 1.24 & $0.290^{*}$ & $1.647^{\star \star}$ & $0.764^{* *}$ & & \\
\hline
\end{tabular}

${ }^{*} p \leq 0.05$ and ${ }^{* *} p \leq 0.01$

Table 2. Continued

\begin{tabular}{|c|c|c|c|c|c|c|c|c|c|c|c|c|}
\hline \multirow{3}{*}{ Env. } & \multicolumn{12}{|c|}{ Characters } \\
\hline & \multicolumn{6}{|c|}{ Number of sterile grains per panicle } & \multicolumn{6}{|c|}{ Yield } \\
\hline & BAU125 & BR5 & Kalizira & Katari & Mean & $\begin{array}{l}\text { Env. } \\
\text { Index }\end{array}$ & BAU125 & BR5 & Kalizira & Katari & Mean & $\begin{array}{l}\text { Env. } \\
\text { Index }\end{array}$ \\
\hline Env.1 & 12.2 & 30.2 & 25.5 & 28.2 & 24 & -0.02 & 3.4 & 3 & 2.8 & 3.1 & 3.1 & 0.29 \\
\hline Env.2 & 12.1 & 12.9 & 31.6 & 26.1 & 20.7 & -3.36 & 3.5 & 4.1 & 3.5 & 3.1 & 3.5 & 0.77 \\
\hline Env.3 & 12 & 28.2 & 18.7 & 26.9 & 20.5 & -3.57 & 2.9 & 2.5 & 2.4 & 2.7 & 2.6 & -0.16 \\
\hline Env.4 & 25.8 & 20.3 & 20.6 & 21 & 21.9 & -2.11 & 3.7 & 3.5 & 3.4 & 3.1 & 3.4 & 0.64 \\
\hline Env.5 & 14.6 & 25.4 & 24.4 & 17.6 & 20.5 & $\begin{array}{l}-3.57 \\
\end{array}$ & 2.5 & 2.4 & 1.7 & 2.2 & 2.2 & $\begin{array}{l}-0.64 \\
\end{array}$ \\
\hline Env.6 & 11.5 & 30.6 & 31.1 & 34.2 & 26.9 & 2.82 & 3.4 & 2.4 & 2.3 & 2.8 & 2.7 & -0.55 \\
\hline Env.7 & 12.8 & 15.4 & 16.2 & 17.2 & 15.4 & -8.65 & 3.2 & 2.3 & 2.4 & 2.8 & 2.7 & -0.7 \\
\hline Env.8 & 17.3 & 33.7 & 24.5 & 35.7 & 27.8 & 3.76 & 2.3 & 1.5 & 2.2 & 2.2 & 2.1 & -0.03 \\
\hline Env.9 & 17.3 & 34 & 34.8 & 68.8 & 38.7 & 14.69 & 2.7 & 2.4 & 2.4 & 2.9 & 2.6 & -0.08 \\
\hline Mean & 15.07 & 25.64 & 25.27 & 30.21 & 24.04 & & 3.07 & 2.66 & 2.56 & 2.74 & 2.8 & \\
\hline $\mathrm{Pi}$ & -8.98 & 1.59 & 1.22 & 6.16 & & & 0.31 & -0.1 & -0.2 & -0.02 & & \\
\hline $\mathrm{bi}$ & 0.145 & $0.853^{* \star}$ & $0.698^{\star *}$ & $2.304^{\star \star}$ & & & $0.888^{* *}$ & $1.433^{* *}$ & $1.064^{* *}$ & $0.616^{\star *}$ & & \\
\hline $\mathrm{S}^{2} \mathrm{di}$ & $18.389^{\star *}$ & $27.270^{\star *}$ & $15.238^{\star *}$ & $15.658^{\star *}$ & & & $0.038^{* *}$ & $0.076^{* *}$ & $0.047^{* *}$ & $0.022^{\star \star}$ & & \\
\hline
\end{tabular}

${ }^{*} p \leq 0.05$ and ${ }^{* *} p \leq 0.01$ 


\section{Plant height}

The average plant height $(\mathrm{cm})$ of individual genotype over nine environments with their regression coefficient and deviation from regression are presented in Fig. 1a. From the environmental mean it was observed that Env.-2 was the most favorable than others for producing lowest plant height. The lowest plant height produced by the genotype BR5. The phenotypic indices of Kalizira, BR5 and BAU125 were positive, therefore, they are desirable genotypes for this character. The two genotypes Kalizira and Kataribhog showed combined bi and $s^{2} d_{i}$ sensitivity suggesting both linear and non-linear component were responsible for genotype-environment interaction. The genotype BAU125 and BR5 showed significant $s^{2} d_{i}$ values which indicate that they were more affected by the environmental fluctuations i.e. performance of these genotypes over environments were unpredictable. In all the three parameters, genotype BR5 appeared to be stable than other genotypes that having bi value near to unity with positive phenotypic indices.

\section{Effective tillers}

The average number of effective tillers per hill of the individual genotype along with $p_{i}$, bi and $s^{2} d_{i}$ are presented in Fig. 1b. From the environmental mean it was observed that Env.-7 had the highest 13.5 tillers per hill and Env.2 had the lowest 9.3 tillers per hill. Analysis of stability parameters of individual genotype indicated that none of the genotypes showed combine $b_{i}$ and $s^{2} d_{i}$ sensitivity and as a result there is no cumulative effect of linear and non-linear components for significant genotype-environment interaction. BAU125 and BR5 had the positive phenotypic indices, therefore, they were desirable for this character. BR5, Kalizira and Kataribhog had the higher $b_{i}$ value with non-significant $s^{2} d_{i}$ indicating their suitability for growing better environmental conditions. Taking all the three stability parameters, genotype BAU125 was considered stable and desirable genotype for number of effective tillers per hill.

\section{Panicle length}

The stability parameters along with the average length of panicle $(\mathrm{cm})$ in different genotypes and environment are presented in Table 2. From the environmental mean it was observed that Env.-7 was the favorable and Env.-4 was the most unfavorable one. Analysis of stability parameters of individual genotypes indicated that all the four except one (BAU125) showed combined $b_{i}$ and $s^{2} d_{i}$ sensitivity suggesting either linear or non-linear component alone or their cumulative effects were responsible for significant genotype-environment interaction. Genotypes BAU125 and Kataribhog had the positive phenotypic indices, therefore, they were desirable for this character. The significant $b_{i}$ value with nonsignificant $\mathrm{s}^{2} \mathrm{~d}_{\mathrm{i}}$ of BAU125 genotype indicating its suitability for growing in better environmental condition. Considering all the three parameters $\left(p_{i} b_{i}\right.$ and $\left.s^{2} d_{i}\right)$ the genotype BAU125 was found relatively stable among all the genotypes.

\section{Fertile grains per panicle}

The average number of fertile grains per panicle of individual genotype over nine environments with their regression co-efficient and deviation from regression are presented in Fig. 1c. From the environmental mean it was observed that Env.-7 was the most favorable and Env.-9 was the unfavorable one. The highest number fertile grains per panicle (143.18) were produced by BR5 and the lowest number of fertile grains per panicle (104.45) was produced by BAU125. The phenotypic indices of BR5 and Kalizira were positive, therefore, they were desirable genotypes for this character. Analysis of the stability parameters of the individual genotypes indicates that the genotypes BAU125, BR5 and Kalizira showed combined bi and $s^{2} d_{i}$ sensitivity suggesting both linear and non-linear components were responsible for genotypeenvironment interaction. Kalizira had higher bi value with non -significant $s^{2} d_{i}$ indicating its suitability for growing in better environmental condition. In all the stability parameters genotype Kalizira was found comparatively stable among others for this character. 


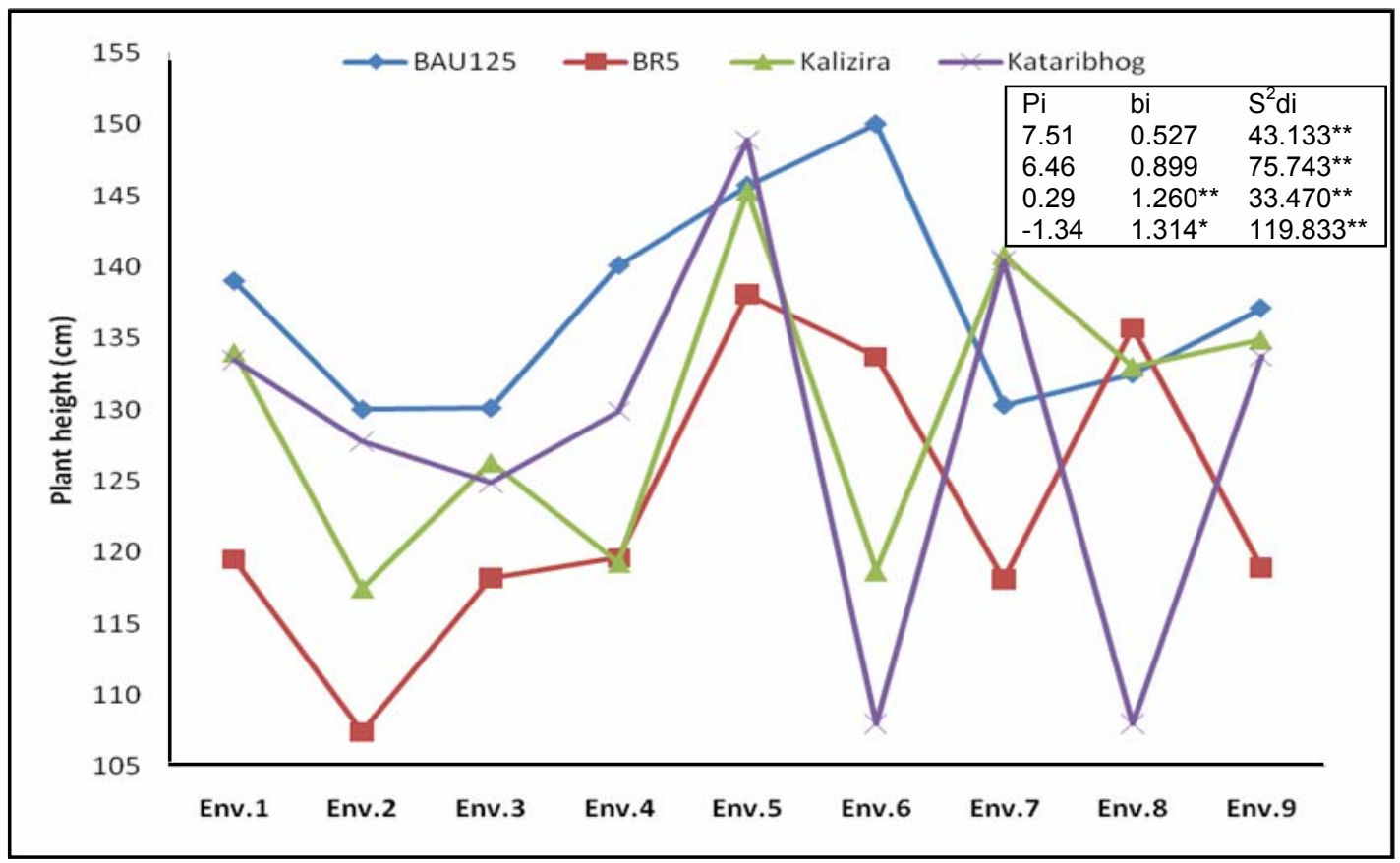

Fig. 1a. Average plant height and phenotypic index $(\mathrm{Pi})$, regression (bi) and deviation from regression $\left(\mathrm{S}^{2}\right.$ di) for four rice genotypes evaluated under nine different environments using Eberhart and Russell model

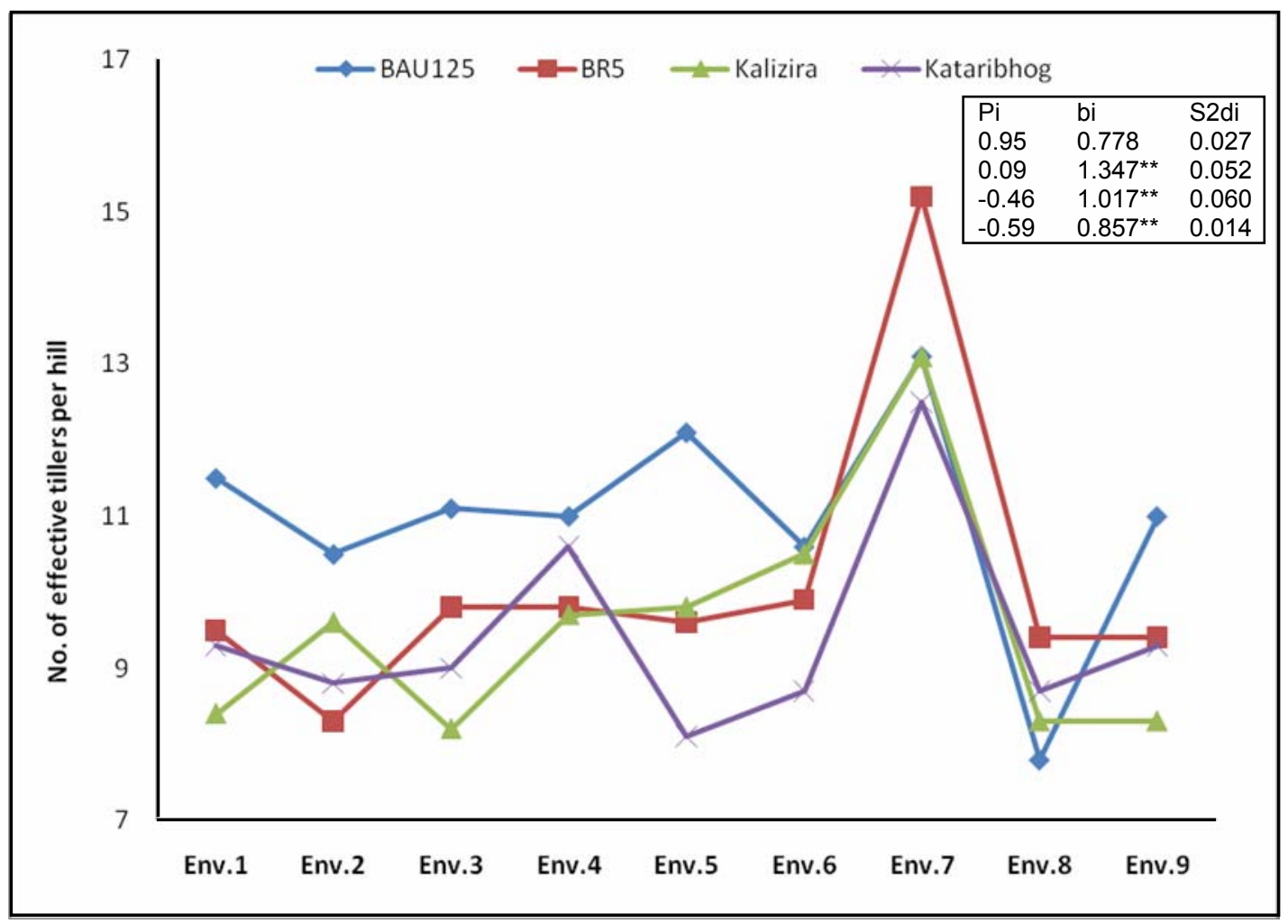

Fig. 1b. Average number of effective tillers per hill and phenotypic index (Pi), regression (bi) and deviation from regression $\left(S^{2}\right.$ di) for four rice genotypes evaluated under nine different environments using Eberhart and Russell model 


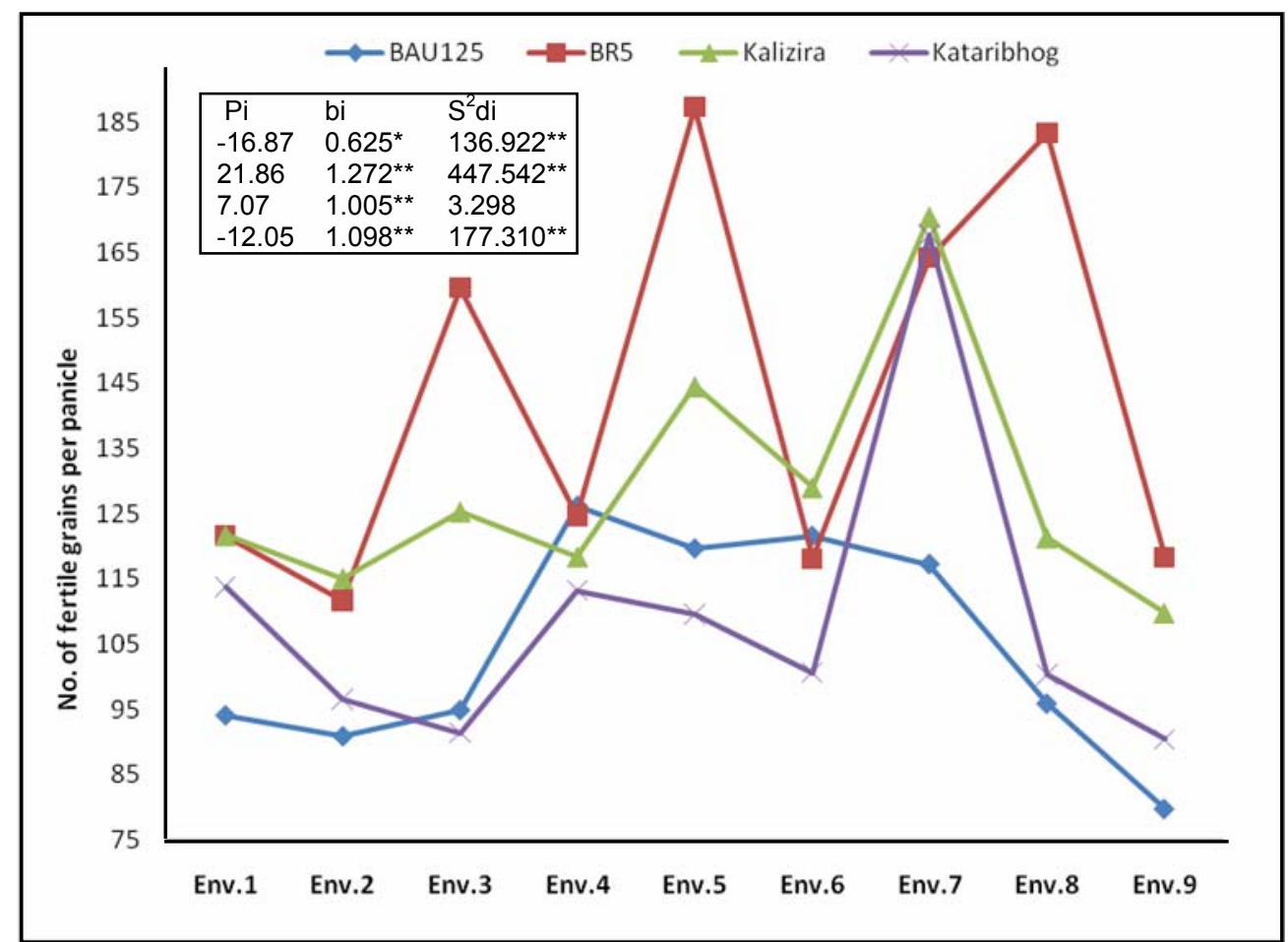

Fig. 1c. Average number of fertile grains per panicle and phenotypic index (Pi), regression (bi) and deviation from regression $\left(\mathrm{S}^{2} \mathrm{di}\right)$ for four rice genotypes evaluated under nine different environments using Eberhart and Russell model

\section{Sterile grains per panicle}

The mean performance of the individual genotype along with their stability parameters for the number of sterile grain per panicle are presented in Table 2. From the environmental mean it was observed that Env.-7 was the most favorable for the production less number of sterile grains per panicle (15.4). BAU125 genotype produced the lowest average number of sterile grains per panicle (15.07) where Kataribhog showed the highest number of sterile grains per panicle (30.21). Three genotypes BR5, Kalizira and Kataribhog showed combined $b_{i}$ and $s^{2} d_{i}$ sensitivity which suggested that both linear and non-linear components were responsible for significant genotype-environment interaction. The phenotypic indices of BR5, Kalizira and Kataribhog were positive, therefore, they were undesirable genotypes for this character. Genotype BAU125 showed non-significant $b_{i}$ and significant $s^{2} d_{i}$ value indicating it produced higher number of sterile grains per panicle only for highly favorable environment otherwise not. Evaluating all the three parameters $\left(p_{i} b_{i}\right.$ and $s^{2} d_{i}$ ) the genotype BAU125 was found relatively stable for less number of sterile grains per panicle produced among all the genotypes.

\section{Yield}

The average yield performance of the individual genotype along with $p_{i} b_{i}$ and $s^{2} d_{i}$ are presented in Table 2. From the environmental mean it was observed that Env.-2 had the highest mean yield (3.5 t/ha) and the lowest one was obtained in Env.-8 (2.1 t/ha). This indicated that Env.-2 was the most favorable one and the majority of the genotypes had the capacity to exploit that environment to confer the highest yield. Over all the environments, BAU125 showed the highest yield (3.7 t/ha) and Kalizira showed the lowest (2.56 t/ha). Analysis of the stability parameters of the individual genotype indicated that all the four genotype showed combined bi and $\mathrm{s}^{2} \mathrm{~d}_{\mathrm{i}}$ sensitivity suggesting both linear and non-linear component were responsible for significant genotype-environment interaction. Genotypes BR5, Kalizira and Kataribhog showed negative phenotypic indices while BAU125 was positive. BAU 125, BR5 and Kalizira and Kataribhog showed significant $s^{2} d_{i}$ values, thus prediction of their performance over environment would not be authentic. In all the three parameters $\left(p_{i} b_{i}\right.$ and $\left.s^{2} d_{i}\right)$ it was observed that all the genotypes were sensitive to environments i.e. none of the genotypes were found stable against this character. 
The study suggests that genotype BR5 may be selected for stability in days to maturity and plant height. Genotype BAU125 may be selected for effective tillers per hill, panicle length and lowest number of sterile grains per panicle. These materials can be used in fine rice breeding program as a source of genes for stability.

\section{References}

Allard, R.W. and Bradshaw, A.D. 1964. Implication of Genotype-Environment interactions in applied plant breeding. Crop Sci. 4: 503-508.

Dabholkar, A.R., 1992. Elements of Biometrical Genetics. Concept Publishing Company. New Delhi, India. pp: 338-359.

Eagles, H.A. and Frey, K.J. 1977. Repeatability of the stability variance parameter in oats. Crop Sci. 17:253-256.

Eberhart, S.A. and Russel, W.L. 1966. Stability parameters for comparing varieties. Crop. Sci. 6: 36-40.

Morales, A.C., Paragas, A.A. and Carangal, V.R. 1991. Phenotypic stability for grain yield in mungbean (Vigna radiata (L) Wilczek). FLCG Newsletter. 16: 12-15.

Singh, R.K. and Chaudhary, B.D. 1985. Biometrical Methods in Quantitative Genetic Analysis (rev. Ed.). Kalyani Publishers, New Delhi, India. pp: 252-269. 